\title{
IMPLEMENTASI TEKNOLOGI INFORMASI BERBASIS WEB DI BADAN AMIL ZAKAT NASIONAL (BAZNAS)
}

\section{IMPLEMENTATION OF WEB-BASED INFORMATION TECHNOLOGY IN THE AMIL ZAKAT NATIONAL AGENCY (BAZNAS)}

\author{
Nilda Susilawati ${ }^{1}$, Andang Sunarto ${ }^{2}$ \\ IAIN Bengkulu ${ }^{1,2}$ \\ $\underline{\text { nilda79@iainbengkulu.ac.id }}{ }^{1}$
}

\begin{abstract}
National Amil Zakat Agency (BAZNAS) is a means of managing zakat in terms of collecting, distributing and using zakat. The existence of Baznas must continue to be improved through an institutional development strategy so that the management and utilization system can run efficiently, effectively and proportionally can have an impact on improving people's economic lives. One of the strategies used to improve the management of zakat institutions is to optimize the application of web-based information systems as a media to facilitate and improve the efficiency of zakat management in the collection, distribution and utilization of zakat. The results showed a new 34\% BAZNAS in Indonesia that has used the SIMBA application As an application used to perform financial management reports, while for Public and Supporting only a few BAZNAS at the provincial level that has used this because of budget constraints and resources Human.
\end{abstract}

Keywords: BAZNAS, Web-based Information System, Zakat

\section{ASBTRAK}

Badan Amil Zakat Nasional (BAZNAS) adalah cara mengelola zakat dalam hal mengumpulkan, mendistribusikan dan menggunakan zakat. Keberadaan Baznas harus terus ditingkatkan melalui strategi pengembangan kelembagaan sehingga sistem manajemen dan pemanfaatan dapat berjalan secara efisien, efektif dan proporsional dapat berdampak pada peningkatan kehidupan ekonomi masyarakat. Salah satu strategi yang digunakan untuk meningkatkan manajemen lembaga zakat adalah mengoptimalkan aplikasi sistem informasi berbasis web sebagai media untuk memfasilitasi dan meningkatkan efisiensi pengelolaan zakat dalam pengumpulan, distribusi dan pemanfaatan zakat. Hasil penelitian menunjukkan BAZNAS 34\% baru di Indonesia yang telah menggunakan aplikasi SIMBA Sebagai aplikasi yang digunakan untuk melakukan laporan manajemen keuangan, sedangkan untuk Publik dan Mendukung hanya beberapa BAZNAS di tingkat provinsi yang telah menggunakan ini karena keterbatasan anggaran dan sumber daya Manusia.

Kata Kunci: BAZNAS, Sistem Informasi Berbasis Web, Zakat

PENDAHULUAN

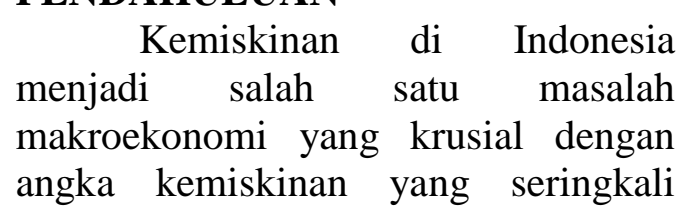

mengalami peningkatan dari waktu ke waktu (Lestari, 2015). Berdasarkan data Badan Pusat Statistik (BPS), jumlah penduduk miskin pada Maret 2017 sebanyak 27,77 juta orang (10,64 
$\%$ ), naik 6,90 ribu orang dibandingkan dengan penduduk miskin pada September 2016 sebanyak 27,76 juta orang $(10,70 \%)$. Penilaian angka kemiskinan ini didasarkan pada konsep kemampuan memenuhi kebutuhan dasar yang dibangun atas garis kemiskinan makanan (GKM) yang dihitung dengan pendekatan kalori minimal sebesar 2100 kkal dan garis kemiskinan bukan makanan (GKBM). Hal ini menunjukkan bahwa pertumbuhan ekonomi belum mampu tumbuh secara merata di wilyah Indonesia.

Berdasarkan data BAZNAS, secara makro, indikator ekonomi tidak bisa dilihat dari pertumbuhan dan juga tingkat pemerataan. Ekonomi diproduksi dalam suatu wilayah perekomian tersebut. Pertumbuhan ekonomi yang tinggi belum tentu mencerminkan pemerataan yang adil. Demikian juga pemerataan yang adil belum menunjukkan pertumbuhan yang tinggi. Bila dilihat dari koofisien Gini Indonesia tahun 2016 dikisaran 0397 pada semester I dan 0394 pada semester II (www.bps.go.id), berarti tingkat pemerataan distribusi pendapatan masih hearts kategori moderat. Kondisi ini lebih baik pada periode 2011-2014 yang mencapai tingkat 0,41 , seharusnya tingkat ketimpngan ideal adalah di bawah 0,3.

Dalam perspektif ekonomi syariah (BAZNAS, 2017), secara makro distribusi pendapatan dapat digunakan dalam tiga aspek yaitu distribusi pra produksi, distribusi pasca produksi dan distribusi ulang. Distribusi pra produksi bertujuan untuk menentukan arah kebijakan meningkatkan pendapat bagi masyarakat miskin, distribusi pasca produksi terkait dengan barang dan jasa yang diproduksi dengan reward yang diterima masing-masing faktor produksi seperti modal, tenaga kerja sesuai dengan kontribusi masing- masing baik through mekanisme pasar maupun investasi pemerintah. Dan ketiga redistibusi yaitu modus penditribusian kekayaan, gerakan ini didasari oleh motif baik adanya ancaman maupun iming-iming yang akan menghasilkan balasan bila mengerjakannya, seperti surat Ali Imran 180 bahwa Allah melarang untuk berbuat bakhil atas harta yang diniliki, karena semua yang dibrikan Allah kepada manusia berupa harta agar dapat berguna bangi orang lain karena semua rezki yang allah berikan kepada manusia hanya titipan dan manuisa harus dapat memanfaatkannya untuk membantu sesam yang membutuhkan. Berdasarkan Berdasarkan sifatnya intrumen redistrbusi harta, isi dan kekayaan dalam Islam ada yang bersifat wajib dan sukarela. Instrumen yang bersifat wajib dikenal dengan zakat sebagaimana firman Allah surat atTaubah 103 yang menjelaskn bahwa Allah menyuruh untuk mengambil harta dari sebagian manusia dengan tujuan untuk membersihkan harta yang dimiliki, karena sebgaian harta itu ada hak orang lain yang harus ditunaikan, sedangkan instumen yang bersifat sukarela seperti infak, sedekah dan wakaf. Keyakinan umat muslim yang di dasarkan pada teori dan kajian dalam al-Qur'an maupun hadis mendorong umat muslm untuk melaksanakan kewajibannya dalm mengentaskan kemiskinan di masyarakat

$$
\text { Prolematika kemiskinan }
$$

merupakan akibat dari distribusi pendapatan dan kekayaan yang tidak merata di tengah-tengah masyarakat. Pemikiran ekonomi telah merumuskan dan memberi solusi tentang bagaimana kemiskinan terjadi dan ditinjau dari beberapa aspek tak terkecuali sosialekonomi. Aspek keadilan sangat mendominasi mengapa kemiskinan dapat terjadi dan bagaimana 
kemiskinan dapat diatasi. Islam telah memberikan solusi praktis untuk mencegah dan mengentaskan kemiskinan dengan konsep redistribusi. Keadilan dalam bidang ekonomi diupayakan oleh pemenuhan kebutuhan pada setiap individu sehingga rasa tanggung jawab sosial pada masing-masing individu yang memiliki kekayaan lebih untuk membantu individu lain yang lebih rendah kekayaannya bahkan tidak cukup memenuhi kebutuhan primer. Hal inilah yang mendasari kewajiban zakat bagi umat Islam (Almas \& Umar, 2018), karena zakat dimanfaatkan untuk kebutuhan produktif (Alim, 2015) agar dapat meningkatkan status sosial mustahik zakat (Ahmad et al., 2015) dan kemandirian muslim (Almas \& Umar, 2018) Kemiskinan yang terus
meningkat, harus

Tabel 1

Pertumbuhan Penyaluran ZISWAF Berdasarkan ASNAF

\begin{tabular}{|c|c|c|c|c|c|}
\hline \multirow{2}{*}{ Asnaf } & \multicolumn{2}{|c|}{ Penyaluran 2015} & \multicolumn{2}{|c|}{ Penyaluran 2016} & \multirow{2}{*}{$\begin{array}{l}\text { Pertumb } \\
\text { uhan } \\
\%\end{array}$} \\
\hline & Jumlah Dana & $\%$ & Jumlah Dana & $\%$ & \\
\hline Fakir Miskin & $1,519,501,961,720$ & 67,56 & $2,143,434,539,579$ & 73.13 & 41.06 \\
\hline Amil & $200,830,665,378$ & 8,93 & $209,233,041,289$ & 7.14 & 4.18 \\
\hline Muallaf & $19,094,327,558$ & 0.85 & $17,403,368,642$ & 0.59 & -8.86 \\
\hline Riqab & $10,569,125,452$ & 0.47 & $4,278,727,729$ & 0.15 & -59.52 \\
\hline Gharimin & $13,282,379,744$ & 0.59 & $16,435,575,105$ & 0.56 & 23.74 \\
\hline Sabilillah & $462,451,321,660$ & 20.56 & $518,991,599,898$ & 17.71 & 12.23 \\
\hline Ibnu Sabil & $23,431,009$ & 1.04 & $21,379,958,163$ & 0.73 & -8.75 \\
\hline Total & $2,249,160,791,525$ & 100 & $2,931,156,809,405$ & 100 & 30.32 \\
\hline \multirow[t]{2}{*}{ Asnaf } & Penyaluran 2015 & & Penyaluran 2016 & & $\begin{array}{l}\text { Pertumb } \\
\text { uhan }\end{array}$ \\
\hline & Jumlah Dana & $\%$ & Jumlah Dana & $\%$ & $\%$ \\
\hline Fakir Miskin & $1,519,501,961,720$ & 67,56 & $2,143,434,539,579$ & 73.13 & 41.06 \\
\hline Amil & $200,830,665,378$ & 8,93 & $209,233,041,289$ & 7.14 & 4.18 \\
\hline Muallaf & $19,094,327,558$ & 0.85 & $17,403,368,642$ & 0.59 & -8.86 \\
\hline Riqab & $10,569,125,452$ & 0.47 & $4,278,727,729$ & 0.15 & -59.52 \\
\hline Gharimin & $13,282,379,744$ & 0.59 & $16,435,575,105$ & 0.56 & 23.74 \\
\hline Sabilillah & $462,451,321,660$ & 20.56 & $518,991,599,898$ & 17.71 & 12.23 \\
\hline Ibnu Sabil & $23,431,009$ & 1.04 & $21,379,958,163$ & 0.73 & -8.75 \\
\hline Total & $2,249,160,791,525$ & 100 & $2,931,156,809,405$ & 100 & 30.32 \\
\hline \multirow[t]{2}{*}{ Asnaf } & \multicolumn{2}{|c|}{ Penyaluran 2015} & \multicolumn{2}{|c|}{ Penyaluran 2016} & $\begin{array}{l}\text { Pertumb } \\
\text { uhan }\end{array}$ \\
\hline & Jumlah Dana & $\%$ & Jumlah Dana & $\%$ & $\%$ \\
\hline Fakir Miskin & $1,519,501,961,720$ & 67,56 & $2,143,434,539,579$ & 73.13 & 41.06 \\
\hline Amil & $200,830,665,378$ & 8,93 & $209,233,041,289$ & 7.14 & 4.18 \\
\hline Muallaf & $19,094,327,558$ & 0.85 & $17,403,368,642$ & 0.59 & -8.86 \\
\hline Riqab & $10,569,125,452$ & 0.47 & $4,278,727,729$ & 0.15 & -59.52 \\
\hline
\end{tabular}




\begin{tabular}{|c|c|c|c|c|c|}
\hline Gharimin & $13,282,379,744$ & 0.59 & $16,435,575,105$ & 0.56 & 23.74 \\
\hline Sabilillah & $462,451,321,660$ & 20.56 & $518,991,599,898$ & 17.71 & 12.23 \\
\hline Ibnu Sabil & $23,431,009$ & 1.04 & $21,379,958,163$ & 0.73 & -8.75 \\
\hline Total & $2,249,160,791,525$ & 100 & $2,931,156,809,405$ & 100 & 30.32 \\
\hline \multirow[t]{2}{*}{ Asnaf } & Penyaluran 2015 & & Penyaluran 2016 & & $\begin{array}{l}\text { Pertumb } \\
\text { uhan }\end{array}$ \\
\hline & Jumlah Dana & $\%$ & Jumlah Dana & $\%$ & $\%$ \\
\hline Fakir Miskin & $1,519,501,961,720$ & 67,56 & $2,143,434,539,579$ & 73.13 & 41.06 \\
\hline Amil & $200,830,665,378$ & 8,93 & $209,233,041,289$ & 7.14 & 4.18 \\
\hline Muallaf & $19,094,327,558$ & 0.85 & $17,403,368,642$ & 0.59 & -8.86 \\
\hline Riqab & $10,569,125,452$ & 0.47 & $4,278,727,729$ & 0.15 & -59.52 \\
\hline Gharimin & $13,282,379,744$ & 0.59 & $16,435,575,105$ & 0.56 & 23.74 \\
\hline Sabilillah & $462,451,321,660$ & 20.56 & $518,991,599,898$ & 17.71 & 12.23 \\
\hline Ibnu Sabil & $23,431,009$ & 1.04 & $21,379,958,163$ & 0.73 & -8.75 \\
\hline Total & $2,249,160,791,525$ & 100 & $2,931,156,809,405$ & 100 & 30.32 \\
\hline
\end{tabular}

Sumber : Statistik Zakat Nasional (2017)

Undang-undang Republik

Indonesia Nomor 23 tahun 2011 tentang pengelolaan zakat dan Peraturan Pemerintah Republik Indonesia nomor 14 tahun 2014 dijelaskan bahwa BAZNAS merupakan lembaga yang berwenang melakukan tugas pengeloaan zakat secara nasional dan menyelenggarakan fungsi perencanaan, pelaksanaan dan pengendalian dan pelaporan atas pengumpulan, penyaluran dan pendayagunaan zakat (Turmudi, 2015)

Secara prakteknya pengelolaan zakat di Indonesia belum optimal dalam pengelolaan dan penyalurannya karena masih kurangnya standar sumber daya manusia yang mengelola dana zakat. Di tambah kelemahan lainnya dalam pengeloaan zakat dari aspek yuridis, sosiologis, institusional dan manajemen berdasarkan kelemahan tersebut maka peran negara dalam pengelolaan zakat terdapat empat pilar yaitu peran negara sebagai regulator, peran negara sebagai fasiliator, peran negara sebagai motivator dan peran negara sebagai distributor (Ahmad et al, 2015).

Lembaga zakat merupakan sarana pengelolaan zakat dari segi pengumpulan, pendistribusian dan pendagunaan zakat (Anofrizen, 2016). Eksistensi lembaga zakat harus terus ditingkatkan melalui strategi pengembangan lembaga agar sistem pengelolaan dan pendayagunaan dapat berjalan dengan efisien, efektif dan proporsional dapat berdampak kepada peningkatan kehidupan ekonomi masyarakat. Strategi yang digunakan untuk meningkatkan pengelalaan lembaga zakat salah satunya dengan mengoptimalisasi penerapan aplikasi teknologi informasi sebagai media untuk memudahkan dan efisiensi pelaksanaan pengelolaan zakat baik itu pengumpulan, pendistribusian dan pendayagunaan zakat. Berdasarkan data dari Sistem Informasi manajemen BAZNAS bahwa aplikasi yang telah diterapkan sejak tahun 2011 telah menunjukkan peningkatan singnifikan dari entri data yang digunakan oleh masing-masing lembaga zakat yang ada di Indonesia, sebagaimana dalam tabel berikut:

Tabel 2

Data OPZ dan SIMBA

\begin{tabular}{|c|c|c|c|c|}
\hline No & OPZ & $\begin{array}{l}\text { Terdaftar } \\
\text { pada } \\
\text { SiMBA }\end{array}$ & Total & Capaian \\
\hline 1 & BAZNAS & 1 & 1 & $100 \%$ \\
\hline 2 & $\begin{array}{l}\text { BAZNAS } \\
\text { Propinsi }\end{array}$ & 33 & 34 & $97,00 \%$ \\
\hline 3 & $\begin{array}{l}\text { BAZNAS } \\
\text { Kab/Kota }\end{array}$ & 462 & 514 & $89,69 \%$ \\
\hline 4 & LAZ & 8 & 26 & $30,77 \%$ \\
\hline
\end{tabular}

Sumber data: SiMBAZNAS 
Sistem teknologi informasi digunakan lembaga untuk membantu dalam pengelolaan, menentukan kebijakan strategis (Setiawan \& Khairuzzaman, 2017)., penyimpanan dan pengelolaan data master agar dapat didokumentasikan dengan baik (Ananda 2014). Penerapan aplikasi teknologi informasi zakat diharapkan mampu memudahkan pengelola lembaga zakat dalam mengelola zakat dan memberikan informasi yang luas kepada masyarakat tentang kemudahan masyarakat berzakat hanya dengan menggunakan aplikasi zakat yang ada. Namun berdasarkan hasil data BAZNAS tahun 2017 bahwa pengumpulan zakat baru mencapai 6 triliun, mengalami kenaikan dari tahun 2016 sebesar 5,12 triliun (Baznas, 2017). Dari potensi zakat yang mencapai 217 triliun, artinya baru 0,2 persen dana zakat yang terserap (Baznas, 2017). Hal ini menjadi persoalan karena aplikasi sistem manajemen informasi yang telah diluncurkan sejak tahun 2012 belum mampu memberikan kontribusi maksimal dalam pengelolaan zakat. Aplikasi yang merupakan perangkat hardware dan software yang dioperasionalkan dengan tujuan untuk memberikan data dan informasi tentang pengelolaan zakat.

Aplikasi sistem informasi berbasis web yang digunakan di BAZNAS terdiri dari tiga aplikasi yaitu ERP, SiMBA, Public dan Supporting. ERP merupakan aplikasi keuangan, aplikasi internet portal dan lainnya yang berfungsi untuk mendukung operasional koordinator dan monitoring yang digunakan oleh BAZNAS Pusat. SiMBA merupakan Sistem Informasi Manajemen berbasis web di Badan Amil Zakat Nasional yang berfungsi untuk mencetak laporan standar nasional yang digunakan di BAZNAS daerah dan Lembaga Amil
Zakat (LAZ). Aplikasi Publik merupakan website, muzakki Corner (Platform Web, Androit, iPhone), Publik Dashboard, dan lainnya dimana aplikasi ini dapat digunakan masyarakat yang berfungsi sebagai media sosialisasi dan edukasi. Aplikasi Supporting yaitu aplikasi yang memberikan informasi tentang program Zakat Community Development (ZCD), aplikasi rumah sehat, Aplikasi BTB dan lainnya (Baznas, 2017).

Sistem informasi berbasis web di BAZNAS merupakan sistem atau aplikasi yang dapat meningkatkan efisiensi pencatatan dan pengelolaan transaksi zakat dari warga dan juga dapat diakses secara bersamaan sehingga proses penerimaan zakat dapat terintegrasi. Kemudahan akses informasi ini dapat memotivasi para mustahik untuk menyalurkan dananya melalui lembaga zakat, sehingga pengelolaan dan pendayagunaan zakat dapat terigrasi secara maksimal.

\section{METODE PENELITIAN}

Penelitian ini dilakukan dengan penelitian field reseach dengan pendekatan kualitatif untuk menggambaran penggunaan web sebagai media dalam pengumpulan maupun pendayagunaan zakat dan fungsi perangkat tersebut dalam memaksimalkan pengumpulan dan pengelolaan zakat. Sumber data primer diperoleh dari pimpinan dan pengelola BAZNAS pusat, BAZNAS DIY, BAZNAS Jawab Barat, BAZNAS Sumatera Barat dan BAZNAS Propinsi Bengkulu yang mengetahui tentang pengaplikasian website dan pengelola keuangan dan pendayagunaan zakat dan data sekunder diperolah melalui website dan data yang dimiliki oleh BAZNAS dalam pengelolaan zakat.

Pengumpulan data dilakukan melalui observasi dalam penggunaan web dengan memperhatikan beberapa 
menu dalam dan tampilan web yang dapat mempermudah calon muzaki atau masyarakat dalam mengakses informasi yang disediakan dalam web, wawancara juga dilakukan kepada pimpinan dan pengelola lembaga zakat tentang informasi penggunaan website, fitur yang ada dan kemudahan akses yang bisa digunakan oleh masyarakat dan diperkuat juga melalui data-data keuangan dalam pengumpulan dan pengelolaan dana zakat melalui web.

Data yang diperoleh diklasifikasi dan disajikan dalam bentuk uraian kemudian dianalisis untuk menggambarkan informasi yang diperolah agar data yang disajikan lebih terstuktur dan sistematis

\section{HASIL DAN PEMBAHASAN}

Penerapan Aplikasi Teknologi Informasi Zakat (ERP, SiMBA, Public, Supporting)

Sistem informasi yang digunakan oleh BAZNAS RI terdiri dari empat macam sistem yaitu SIMBASNAS, ERP, Publik dan Support. SIMBAZNAS yang digunakan oleh BAZNAS sudah dimulai sejak tahun 2012 dimana aplikasi ini memuat data pengelolaan zakat yang meliputi data pengumpulan dan penyaluran zakat.

Aplikasi SIMBAZNAS hanya digunakan untuk pengelolaan zakat, artinya masyarakat umum tidak dapat mengakses SIMBAZNAS karena sistem informasi ini hanya diperuntukkan untuk pengelola lembaga zakat di seluruh Indonesia. Data yang berkaitan dengan pengumpulan data akan diiput oleh admin setiap harinya sesuai dengan jumlah dana zakat yang masuk, sebaliknya penyaluran zakat baik itu bersifat konsumtif maupun produktif juga terdata dengan baik di SIMBAZNAS.
Aplikasi teknologi informasi yang digunakan oleh BAZNAS Pusat terdiri dari :

1. SIMBAZNAS (Sistem Informasi BAZNAS) yang hanya digunakan oleh BAZNAS Pusat, sedangkan SIMBA (Sistem Informasi Badan Amil) digunakan oleh BAZNAS daerah dan Lembaga Amil Zakat (LAZ)

2. ERP (Enterprise Resource Planning) adalah sistem informasi yang diperuntukkan untuk BAZNAS dalam mengintegrasikan dan mengotomasikan sistem pengelolaan zakat di BAZNAS Pusat dan sistem ini hanya diterapkan di BAZNAS Pusat

3. Publik, adalah sistem informasi yang digunakan oleh publik, artinya masyarakat dapat memperolah informasi secara terbuka terkait pengelolaan zakat seperti penerimaan dana zakat maupun penyaluran zakat melalui program-program pemberdayaan zakat seperti dalam bidang ekonomi, sosial maupun pendidikan. Salah satunya melalui website BAZNAS dengan alamat http://.baznas.go.id

4. Support, digunakan oleh mitra BAZNAS seperti GoPay dengan aplikasi GoZakat.

Software yang digunakan oleh BAZNAS dalam aplikasi pengelolaan zakat yaitu:

1. Jenis SIMBA (Sistem Manajemen Infromasi BAZNAS) melalui https://simba.baznas.go.id/ dengan kegunaan untuk mengelola zakat mulai dari manajemen muzakki, mustahik, pengumpulan, penyaluran dan operasional sampai pencetakan laporan keuangan.

2. Jenis ERP (Enterprise Resource Planning) dengan menggunakan Internet Portal (iPortal) yang 
digunakan sebagai sistem monitoring pengelolaan zakat yang dilakukan oleh BAZNAS RI dan Sistem Informasi Keuangan (SIMKEU) untuk mengelola akunting dan mencetak laporan keuangan BAZNAS RI. (PID BAZNAS RI, 2019)

Penggunaan SIMBA sudah disosialisasikan sejak tahun 2010 namun baru efektif tahun 2013, karena BAZNAS harus menyiapkan perangkat softwere dan admin yang akan mengelola aplikasi SIMBA. Dan kemudahan dari aplikasi SIMBA adalah laporan keuangan dengan mudah dipantau oleh pengelola.

BAZNAS RI menggunakan aplikasi SIMBA dalam pengelolaan keuangan yang harus diterapkan oleh seluruh BAZNAS di Indonesia dan dikembangkan lagi dengan aplikasi lainnya agar dapat mendukung pengelolaan zakat di lembaga zakat di Indonesia. Seperti di BAZNAS Jawa Barat berkerjasama dengan Kitabisa.com, Gopay, LinkAja, Wecare.id. BAZNAS Jawa Barat juga melakukan kerjasama dengan perbankan seperti BCA, BRI, BNI Syariah, BJB Syariah, Bank Mandiri, Bank Syariah melalui pembayaran zakat via ATM. Sedangkan untuk sistem informasi publik menggunakan website dan ERP tidak digunakan karena hanya digunakan oleh BAZNAS RI untuk mengintegrasi sistem informasi dengan BAZNAS daerah.

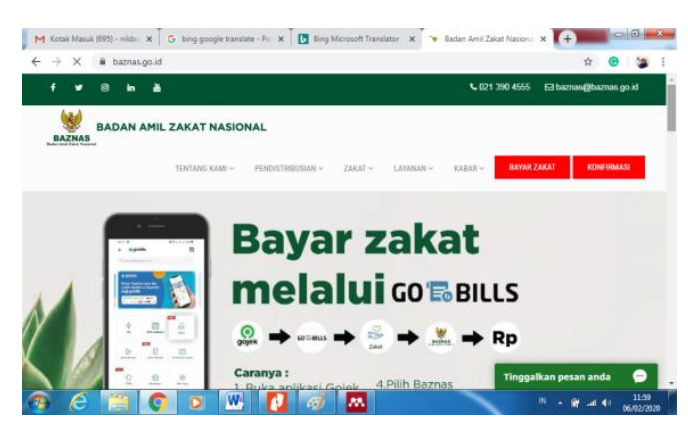

Gambar 1. Tampilan sistem BAZNAS

Sebagai upaya untuk menjaga akuntabilitas pengelolaan keuangan di lembaga zakat khususnya BAZNAS Propinsi Sumatera Barat juga menyampaikan laporan setiap 6 bulan sekali dan diaudit oleh inspktorat, audit syariah oleh Perguruan Tinggi dan Kemenag serta audit keuangan oleh inspketorat dan Bimbingan Sosial Kesra Pemda. Pelaksanaan audit sudah dilaksanakan sejak tahun 2016 dan pelaksanaannya setiap satu tahun sekali. Hal ini dilakukan untuk menjaga kepercayaan masyarakat dalam pengelolaan keuangan.

Berdasarkan informasi dari Pengelola Informasi dan Dokumentasi BAZNAS RI bahwa jumlah zakat yang masuk ke dalam sistem dari pengumpulan zakat :

Tabel 3 Sistem Pengumpulan Zakat

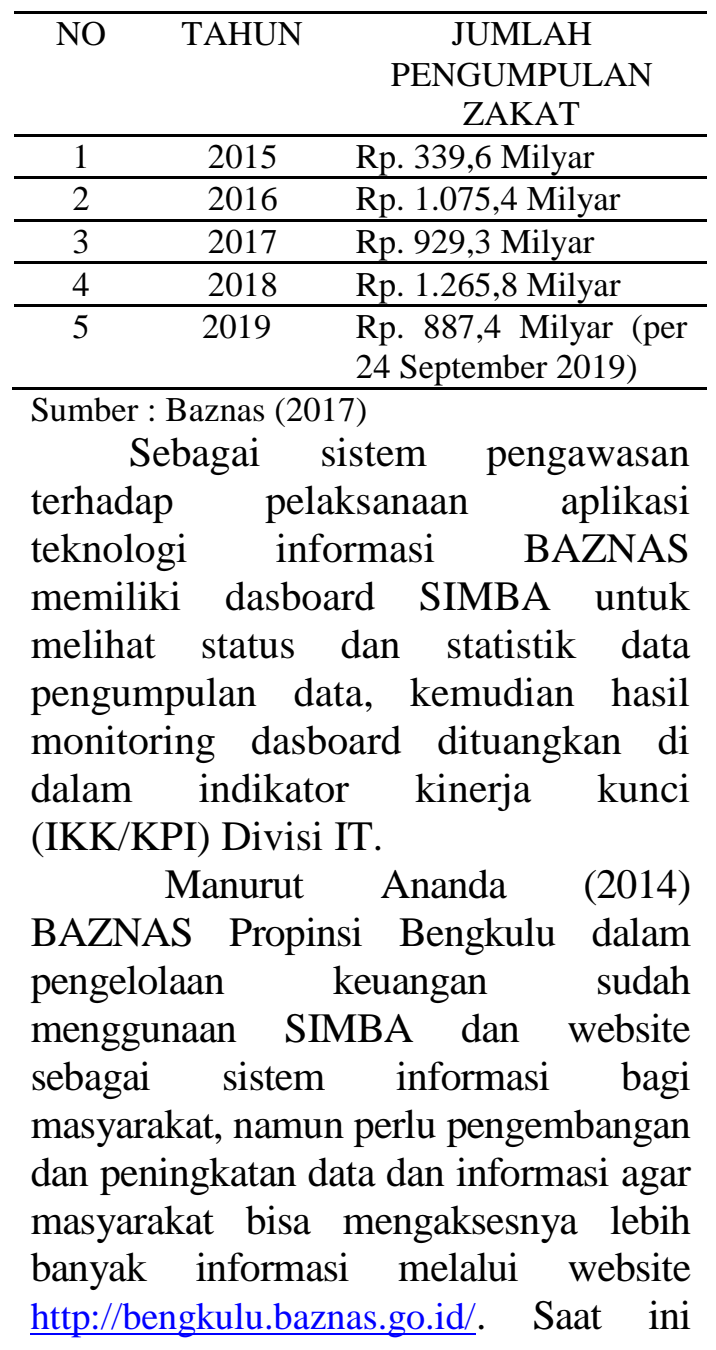


BAZNAS Propinsi Bengkulu sedangkan dalam proses penyempunaan website dan akan melalukan kerjasama dengan beberapa aplikasi untuk memudahkan sistem pembayaran zakat. Karena selama ini zakat hanya dibayar secara lansung oleh masyarakat ke BAZNAS, artinya belum menggunakan aplikasi. Selain itu penggunaan SIMBA baru maksimal digunakan ditingkat Propinsi, sementara untuk BAZNAS kabupaten masih ada yang belum menggunakan SIMBA, artinya penyampaian laporan masih bersifat manual, dan ini menjadi pekerjaan tambahan bagi BAZNAS Propinsi untuk menginput data dari BAZNAS Kabupaten ke aplikasi SIMBA.

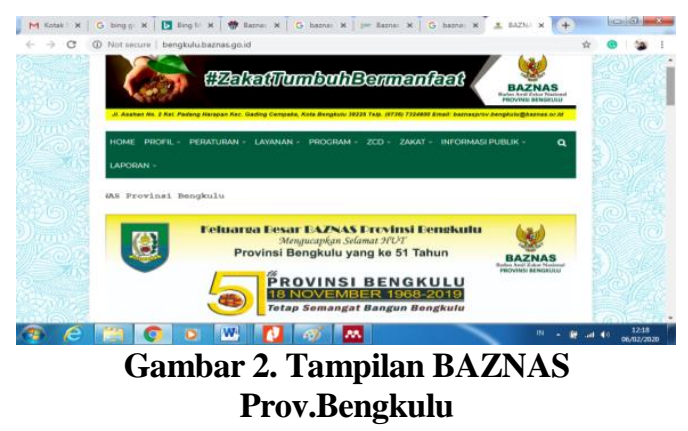

\begin{abstract}
BAZNAS Jawa Barat dalam penggunaan aplikasi informasi menggunakan website dengan alamat http://baznasjabar.org dimana melalui website disediakan berbagai fitur yang dapat membantu masayarakat dalam mencari informasi tentang pengelolaan zakat, baik itu cara pembayaran zakat melalui website sudah disediakan kalkulator yang dapat membantu calon muzakki dalam menghitung harta yang akan dikeluarkan zakatnya.
\end{abstract}

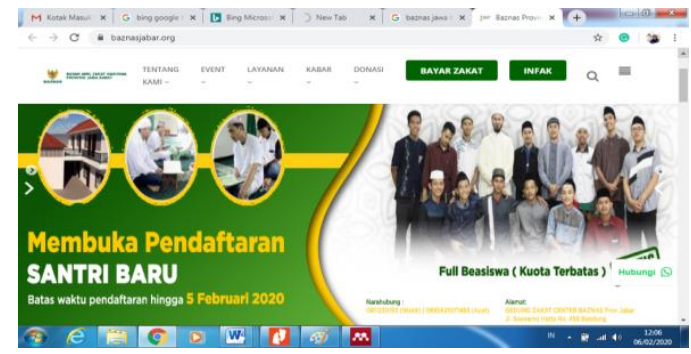

Gambar 3. Tampilan BAZNAS Jawa Barat
Selain itu BAZNAS Jawa Barat juga menggunakan kanal pembayaran digital ZIS ke BAZNAS Jawa Barat melalui aplikasi dan media sosial seperti Kitabisa.com, Gopay, LinkAja, Wecare.id. BAZNAS Jawa Barat juga melakukan kerjasama dengan perbankan seperti BCA, BRI, BNI Syariah, BJB Syariah, Bank Mandiri, Bank Syariah melalui pembayaran zakat via ATM, informasi ini dapat diketahui dari laman infromasi website BAZNAS Jawa Barat. Dan berdasarkan data statistik ZIS Se Propinsi Jawa Barat bahwa penghimpunan dana zakat mencapai 80.1 Milyar dan yang sudah disalurkan sebesar 69.1 Milyar dengan 10 ribu muzakki. Dan dalam pengelolaan zakat BAZNAS Jawa Barat juga menggunakan SIMBA yng dapat diakses oleh pengelola BAZNAS.

Untuk BAZNAS Propinsi Sumatera Barat, karena hanya menggunakan SIMBA yang hanya dapat diakses oleh admin, sedangkan sistem informasi lainnya belum digunakan, maka penggunakan sistem informasi belum dapat dilaksanakan secara maksimal. Selain itu masyarakat juga cenderung datang langsung ke BAZNAS dalam membayar zakat, sehingga penggunaan aplikasi sistem informasi belum dirasakan oleh BAZNAS Propinsi Sumatera Barat.

BAZNAS di Indonesia secara bersama mengoptimalkan sistem informasi yang ada, agar tingkat kepecayaan masyarakat terhadap pengelolaan zakat terus meningkat, karena hal ini dapat memaksimalkan pengumpulan zakat yang potensinya cukup besar. Zakat sebagai salah satu cara dalam mengurangi kemiskinan di Indonesia diupayakan melalui strategi pengelelolaan zakat berbasis teknologi informasi (Alim, 2015). 
Kendala dalam Penerapan Aplikasi Teknologi Informasi Zakat di Badan Amil Zakat Nasional

Kendala yang dihadapi oleh BAZNAS RI dalam pelaksanaan operasional aplikasi pengelolaan zakat adalah mendapatkan data agar sesuai dengan data riil pengumpulan zakat di Indonesia. Data ini masih minim karena OPZ baru tercatat sekitar $34 \%$ yang dianggap menggunakan SIMBA. Aplikasi SIMBA adalah aplikasi dengan skema SaaS (Sofware as a Service) jadi kendala teknologi bisa dipastikan tidak ada dari sisi user.

Dalam aplikasi SIMBA untuk BAZNAS di tingkat Propinsi belum mengalami kendala yang signifikan, karena BAZNAS RI sebelum melouncing penggunaan aplikasi SIMBA untuk diterapkan di seluruh Indonesia sudah melakukan sosialisasi dan pelatihan bagi user, hanya saja untuk BAZNAS di tingkat Kabupaten masih ada beberapa BAZNAS yang belum menggunakan aplikasi SIMBA karena keterbatasan sumber daya manusia yang mampu mengoperasikan aplikasi SIMBA dan akses wifi yang belum dimiliki oleh kantor BAZNAS, sehingga pelaporan keuangan masih secara manual BAZNAS di tingkat Propinsi, dan BAZNAS Propinsi nantinya akan menginput data laporan keuangan ke SIMBA. Hal ini membutuhkan waktu, bila masing-masing BAZNAS di tingkat Kabupaten sudah memaksimalkan penggunaan aplikasi SIMBA dalam pelaporan, maka hal ini akan lebih efektif.

Untuk penggunaan aplikasi publik dan support hanya perlu penambahan saja baik itu publik dan support seperti yang sudah dilakukan oleh BAZNAS RI, agar kemudahan untuk membayar zakat dapat dirasakan oleh masyarakat dengan tujuan untuk meningkatkan jumlah zakat yang dibayar oleh masyarakat. Dan perlu perningkatan sosialasi kepada masyarakat tentang penggunaan sistem aplikasi, terutama publik dan support, agar sistem informasi ini dapat dimanfaat secara maksimal bagi masyarakat dalam mengakses infomasi tentang penyaluran dan pengelolaan zakat. Dan selama ini hanya dilakukan melalui informasi media sosial dan media masa dan elektronik (Ananda, et.al, 2014).

Selain itu ketersediaan anggaran untuk membuat aplikasi sistem informasi lainnya berupa website maupun Support menjadai kendala BAZNAS, karena dibuthkan anggaran khusus agar dapat memiliki sistem informasi yang dapat mensosialisasikan semua program pemberdayaan zakat, dan memudahkan akses bagi muzakki yang akan membayar zakat (Ananda et al, 2014).

\section{PENUTUP \\ Kesimpulan}

Potensi zakat yang sedemikian besar menuntut pengelolaan yang profesional dari BAZNAS, baik dari sisi sumber daya manusia maupun organisasi. Dana Zakat tidak hanya berhenti pada penerimaan dan penyaluran zakat saja, tetapi harus ada bentuk pertanggung jawaban seperti laporan keuangan yang akan menjadi jembatan informasi bagi semua pihak yang berkepentingan.

Keberlangsungan lembaga tidak tergantung kepada figur seseorang, tetapi kepada sistem. Akuntabilitas pelaporan zakat mempunyai kaidahkaidah tersendiri yang tidak terdapat pada sistem yang selama ini sudah ada. Sistem informasi berbasis web adalah suatu strategi sistem informasi yang berisi data atau komponen baik fisik maupun non fisik yang saling berinteraksi yang kemudian diolah sedemikian rupa sehingga menghasilkan informasi yang berguna bagi pihak-pihak yang berkepentingan. 


\section{Saran}

Untuk pengembangan lembaga zakat ke depan, maka semua lembaga zakat di Indonesia, baik tingkat Propinsi maupun tingkat kota/Kabupaten sudah harus menggunaan sistem informasi zakat minimal SIMBA sebagai aplikasi resmi BAZNAS dalam pengelolaan keuangan, hanya saja aplikasi ini hanya dapat diakses oleh pengelola saja, sementara masyarakat tidak. Karena itu harus ditambah sistem informasi lain seperti publik/ website, dan support melalui kerjasama dengan beberapa pengguna aplikasi, tujuannya untuk memudahkan masyarakat dalam menyalurkan dana zakat.

Berdasarkan sampel BAZNAS yang diambil terlihat baru beberapa BAZNAS yang secara maksimal sudah menggunakan aplikasi, sementara masih banyak BAZNAS yang belum menggunakan aplikasi dan hanya sebatas SIMBA, dan masih terdapat beberapa wilayah kabupaten yang belum memanfaatkan SIMBA dalam pengelolaan laporan keuangan. Hal ini menjadi perhatian serius bagi lembaga zakat untuk terus meningkatkan akuntabilitas pengelolaan zakat.

\section{DAFTAR PUSTAKA}

Ahmad, R.,A., J., Ahmad, M.,A.,O, \& Muhammad, S.,Y. (2015). Assessing the Satisfaction Level of Zakat Recipients Towards Zakat Management. Procedia Economics and Finance 31 (15): 140-51.

Alim, M.,Z. (2015). Utilization and Accounting of Zakat for Productive Purposes in Indonesia: A Review. Procedia Social and Behavioral Sciences 211 (September): 232-36.

Almas, B., \& Umar, M. (2018) Zakat dan Pajak: Keadilan Redistribusi Perspektif Islam, Jurnal Ilmiah Mahasiswa FEB 3 (2).
Ananda, D. B \& Ari, W. (2014). C4.5 Decision Tree Implementation In Sistem Informasi Zakat (Sizakat) To Automatically Determining The Amount Of Zakat Received By Mustahik. Journal of Information Systems 10 (1): 3037.

Anofrizen. (2016). Sistem Informasi Manajemen Zakat Pada Bazis Desa Srigading Kecamatan Lubuk dalam Kabupaten Siak. Rekayasa 2 (2).

Badan Pusat Statistik. September (2017). Laporan Bulanan Data Sosial Ekonomi, Edisi 88.https://www.bps.go.id/website /pdf_publikasi/Laporan-BulananData-Sosial-Ekonomi

BAZNAS. (2017). Kebangkitan Zakat. BAZNAS Jakarta

Lestari, A. (2015). Efisiensi Kinerja Keuangan Badan Amil Zakat Daerah ( BAZDA ): Pendekatan Data Envelopment Analysis ( DEA ). Jurnal Ekonomi Dan Studi Pembangunan 16: 177-87.

Nurhasanah, S, \& Suryani. (2018). Maksimalisasi Potensi Zakat Melalui Peningkatan Kesadaran Masyarakat. Jurnal Ekonomi Dan Bisnis Islam 3 (2): 186.

Setiawan, H, \& Qadafi, M.,K. (2017). Perancangan Sistem Informasi Manajemen Proyek. Jurnal Khatulistiwa Informatika 5 No. (2): 103-11.

Turmudi, M. (2015). Pajak Dalam Perspektif Hukum Islam (Analisa Perbandingan Pemanfaatan Pajak dan Zakat). Al-'Adl, 8(1), 128142. 